\title{
Rebreathing expired gases from bedding: a cause of cot death?
}

\author{
David P G Bolton, Barry J Taylor, Angela J Campbell, Barbara C Galland, Chris Cresswell
}

\begin{abstract}
The reported association of cot death and sleeping prone could be due to rebreathing of expired gases. A mechanical model simulating the respiratory system of an infant, exhaling warm humidified air with an end tidal carbon dioxide of $5 \%$, has been used to investigate this. Some commonly used bedding materials caused an accumulation of carbon dioxide of $7 \%$ to over $10 \%$ with the model lying face down. This phenomenon persisted even with the head inclined at $45^{\circ}$, but only on very soft materials, and could be a cause of cot death in a baby unresponsive to asphyxial blood gas changes. A coir fibre mattress allowed complete dispersal of exhalate as did a rubber sheet between any mattress and the covering sheet.

(Arch Dis Child 1993; 69: 187-190)
\end{abstract}

University of Otago

Medical School, PO

Box 913, Dunedin,

New Zealand,

Department of

Physiology

David P G Bolton

Chris Cresswell

Department of

Paediatrics and Child

Health

Barry J Taylor

Angela J Campbell

Barbara C Galland

Correspondence to:

Dr Taylor.

Accepted 4 March 1993
Studies in New Zealand, ${ }^{1}$ Australia, ${ }^{2} 3$ England, ${ }^{4}$ France, ${ }^{5}$ and the Netherlands ${ }^{6}$ have identified the prone sleep position as a major risk factor for sudden infant death syndrome (SIDS). Where community intervention to change babies sleep position away from prone has occurred, there has been marked declines in SIDS and total postneonatal mortality. ${ }^{7} 8$

The mechanism by which lying prone might increase the risk of SIDS in infants is subject to debate. ${ }^{910} \mathrm{~A}$ recent investigation of 25 deaths of infants found prone and face down with nose and mouth buried in a cushion filled with expanded polystyrene beads (of whom 19 were diagnosed as having died of SIDS), concluded

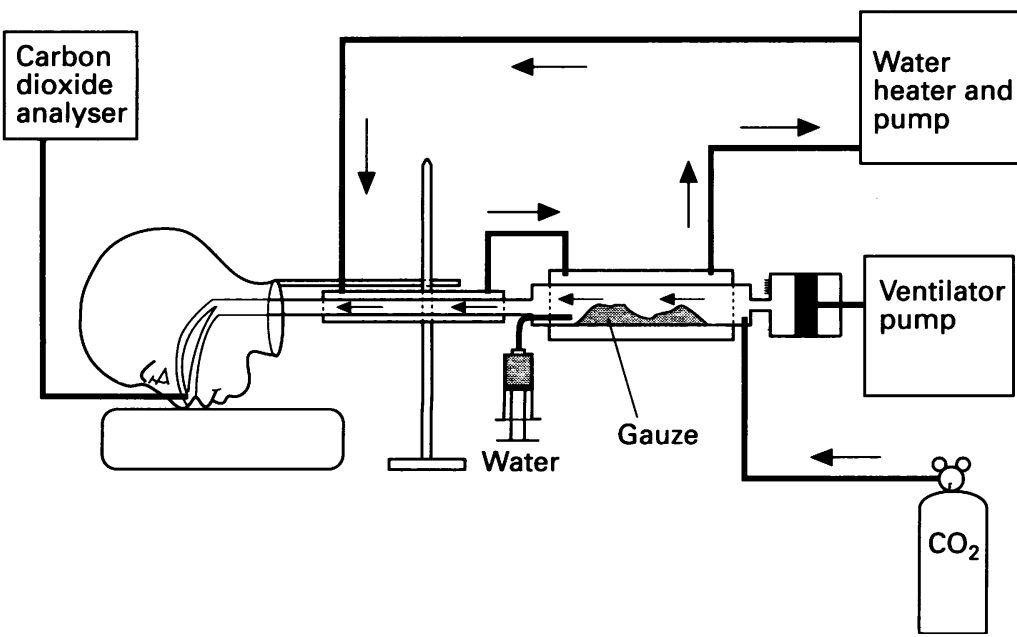

Figure 1 Apparatus for determining rebreathing of carbon dioxide when lying prone. Carbon dioxide was fed into the lungs at a fixed rate comparable with the carbon dioxide production of a 3 month infant. Resulting end tidal carbon dioxide was sampled just inside the nostril. Each breath was warmed and humidified. that accidental suffocation by rebreathing was the likely cause of $22(88 \%)$ of the deaths. ${ }^{11}$

In this study we have used a mechanical model to assess the degree of rebreathing likely to occur in an infant placed to sleep prone with head face down, at $45^{\circ}$ or at $90^{\circ}$ to a variety of sleeping surfaces.

\section{Methods}

THE MODEL

A model of a 3 month old infant's head and respiratory system was constructed similar to that described by Bolton et al (fig 1). ${ }^{12}$ The head was anatomically moulded using silicon plastic and of an appropriate weight for a 3 month infant $(1.3 \mathrm{~kg})$. A motor driven syringe pump (Harvard rodent respirator model 681), was used to ventilate the 'nostrils' at a rate of 40 'breaths' per minute with a 'tidal volume' of $27 \mathrm{ml}$. A glass mixing chamber (volume $=200$ $\mathrm{ml}$ ), together with the pump, formed the equivalent volume of the lungs of a $6 \mathrm{~kg}$ baby. A $10 \mathrm{ml}$ silicone tube connected the 'lungs' to the nostrils to constitute the dead space of the model's ' respiratory system. The tubing divided distally to allow air flow through the two nostrils.

The mixing chamber was warmed by continuously circulating heated water through a surrounding water jacket. The temperature of the water was adjusted so that the temperature of the air reaching the nostrils was always $37 \cdot 0 \pm 0 \cdot 5^{\circ} \mathrm{C}$ at the conclusion of each run. Humidity within the system was provided by placing water soaked gauze within the mixing chamber.

\section{DATA COLLECTION}

Thermistor probes were used to measure temperatures of the air reaching the nostrils (positioned at the end of the dead space tubing) and ambient air (positioned $5 \mathrm{~cm}$ in front of the head). A capacitive humidity probe was used to measure relative humidity at the same ambient site. All data for temperature and humidity were recorded by a multichannel data logger system (Squirrel; Grant Series 1200).

For each experiment, carbon dioxide was continuously trickled into the mixing chamber at a rate of $35 \mathrm{ml}$ per minute which produced an 'alveolar plateau' of about $5 \%$ carbon dioxide (equivalent to an arterial oxygen pressure of $36 \mathrm{~mm} \mathrm{Hg}(4.80 \mathrm{kPa}))$ when the face was unobstructed. Air was sampled from a catheter situated just inside the nostril and the profile of carbon dioxide for each breath was measured by a Normocap carbon dioxide monitor (Datex Instrumentarium Corporation) 
sampling at a rate of $50 \mathrm{ml}$ per minute. This sampling rate was considered to be low enough not to interfere with the build up of gases as it was less than $5 \%$ of the total ventilation. The carbon dioxide monitor was calibrated against standard gases. Pressure within the nostril was recorded using a Grass volumetric pressure transducer (PT5A). The pressure recordings and the tidal volume allowed the resistance to gas flow to be calculated for each bedding material. Outputs from the carbon dioxide monitor and pressure transducer were relayed through the integrated hardware/software system of the MacLab (Analog Digital Instruments Pty Ltd) to an Apple Macintosh Computer (Apple Computer Inc).

\section{HEAD POSITIONING}

The angle between the head's sagittal plane and the horizontal was measured using a brass rod fixed to the back of the head. The rod had a freely rotating, weighted protractor on it, which maintained a vertical position while the head, the brass rod, and a pointer rotated indicating the angle of the head. The weight of the brass rod, pointer, and protractor were included in the $1.3 \mathrm{~kg}$ weight of the head. The head was allowed to rest with its full weight onto the bedding at the specified rotation. Experiments were conducted with the head placed in each of three positions: (i) at $90^{\circ}$ to the bedding, (ii) at $45^{\circ}$ to the bedding, and (iii) face down to the bedding.

\section{BEDDING MATERIALS}

Twenty combinations of under bedding materials commonly used in New Zealand were tested. ${ }^{\star}$ These comprised 12 using either a soft (foam chip or woollen) or hard (coir fibre or foam slab) mattress covered with a cotton sheet with or without a waterproof layer under the sheet. When a waterproof layer was used it was either a 'Protect-a-cot' woollen blanket or a rubber sheet. The remaining combinations tested were sheepskins of four different fibre

Mean (SEM) inspired carbon dioxide (\%) with the face at different angles to common infant under bedding materials

\begin{tabular}{llll}
\hline Sleeping surface & Face to side & Face at $45^{\circ}$ & Face down \\
\hline Hard covered book & $0.18(0)$ & $0.22(0.01)$ & $0.62(0.04)$ \\
Bedding uncovered & & & \\
Sheepskin 15 mm & $0.23(0)$ & $0.55(0.02)$ & $>10$ \\
Sheepskin 30 mm & $0.15(0)$ & $0.57(0.04)$ & $9.95(0.02)$ \\
Sheepskin 40 mm & $0.35(0.02)$ & $8.47(0.29)$ & $>10$ \\
Sheepskin 60 mm & $0.79(0.06)$ & $>10$ & $>10$ \\
Bedding and cotton sheet & $0.18(0)$ & $0.31(0.01)$ & $0.96(0.02)$ \\
Coir fibre mattress & $0.17(0)$ & $0.29(0.01)$ & $1.88(0.09)$ \\
Foam slab mattress & $0.18(0.01)$ & $0.35(0.01)$ & $6.95(0.45)$ \\
Woollen mattress & $0.14(0.01)$ & $0.84(0.03)$ & $>10$ \\
Foam chip mattress & $0.24(0.01)$ & $0.53(0.02)$ & $9.53(0.19)$ \\
Sheepskin 15 mm & $0.27(0.01)$ & $0.68(0.04)$ & $9 \cdot 14(0.25)$ \\
Sheepskin 30 mm & $0.26(0.01)$ & $1.06(0.02)$ & $9.64(0.15)$ \\
Sheepskin 40 mm & $0.33(0.01)$ & $0.89(0.03)$ & $9.43(0.24)$ \\
Sheepskin 60 mm & $0.18(0)$ & $0.30(0.01)$ & $0.93(0.02)$ \\
Woollen waterproof layer between mattress and sheet & $0.17(0)$ & $0.31(0.01)$ & $4.32(0.27)$ \\
Coir fibre mattress & $0.17(0)$ & $0.30(0.01)$ & $2.36(0.14)$ \\
Foam slab mattress & $0.20(0.01)$ & $0.81(0.02)$ & $7.05(0.33)$ \\
Woollen mattress & & \\
Foam chip mattress & & & $0.78(0.03)$ \\
Rubber sheet between mattress and sheet & & $0.96(0.04)$ \\
Coir fibre mattress & & & $1.1(0.03)$ \\
Foam slab mattress & & & $0.88(0.05)$ \\
Woollen mattress & & & \\
Foam chip mattress & & & \\
\hline
\end{tabular}

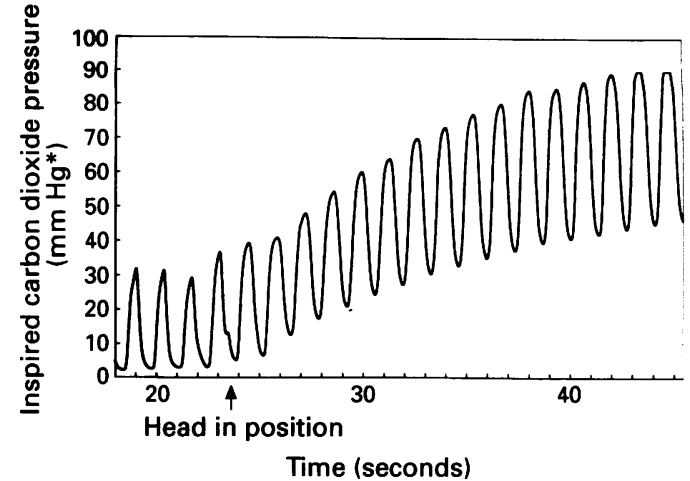

Figure 2 Carbon dioxide profile when face down into sofi bedding. This trace shows the quick rise of inspired carbon dioxide when face down on soft bedding. The arrow indicates when the head is in the appropriate position. $\star 1 \mathrm{~mm} \mathrm{Hg}=0.133 \mathrm{kPa}$.

lengths $(15,30,40$, and $60 \mathrm{~mm})$ either uncovered or covered with a cotton sheet. A hard covered book was used as a control.

\section{EXPERIMENTAL PROTOCOL}

For each run the model was first placed face to the side with the head suspended well above the bedding and table and ventilated as described above until the percentage of inspired carbon dioxide reached equilibrium. Equilibrium was defined as less than $0.2 \%$ change in the inspired carbon dioxide concentrations over 20 seconds. The model was then placed in the test condition and run to equilibrium again. Each experiment was repeated six times in each of the three head positions. Room and head temperature and room humidity were monitored continuously. Humidity and room temperature varied between 30 and $50 \%$ and 20 to $24^{\circ} \mathrm{C}$ respectively and did not correlate with changes in carbon dioxide rebreathing concentrations. Draughts did affect carbon dioxide rebreathing and experiments were therefore carried out in a partitioned off, draught-free area of the laboratory.

A typical time course of an experiment showing carbon dioxide accumulation is shown in fig 2 .

\section{Results}

The table shows the mean (SEM) inspired carbon dioxide concentrations at equilibrium from all surfaces tested.

\section{FACE DOWN TO BEDDING}

The table shows that negligible rebreathing (less than $2 \%$ of carbon dioxide accumulation) occurred with the model placed face down onto the two firm mattresses. The hard covered book also resulted in minimal rebreathing $(0.62(0,04) \%)$. Softer mattresses and all four sheepskins (with or without the cotton sheet covering) showed much greater carbon dioxide accumulation (6.95 to greater than $10 \%$ ).

The average time to reach $10 \%$ inspired carbon dioxide was less than 90 seconds. 
$45^{\circ}$ TO BEDDING

All mattresses tested showed less carbon dioxide accumulation when the head was at $45^{\circ}$ than when placed face down. These concentrations were all negligible (less than $1 \%$ ).

Mean inspired carbon dioxide concentrations at equilibrium for the short wool fibre sheepskins (15 and $30 \mathrm{~mm}$ ) without a cotton sheet were small (less than $1 \%$ ), but reached greater concentrations with the longer fibre lengths $(8.47(0.29)$ and greater than $10 \%$ with 40 and $60 \mathrm{~mm}$ fibre lengths respectively). With a longer fibre length sheepskin the nose, even with the head at $45^{\circ}$, was surrounded by wool. Covering the sheepskins with a cotton sheet produced only small changes on the short wool fibre skins, however, large differences were observed for the longer fibre sheepskins. For $40 \mathrm{~mm}$ fibre lengths without a cotton sheet cover, $8.47 \%$ carbon dioxide accumulation was reduced to $1.06(0.02) \%$ with covering and for $60 \mathrm{~mm}$ fibre lengths, $10 \%$ carbon dioxide accumulation was reduced to 0.89 $(0 \cdot 03) \%$ with covering.

\section{$90^{\circ}$ TO BEDDING}

All surfaces produced negligible carbon dioxide accumulation (less than $0.8 \%$ ) when the model was placed at $90^{\circ}$ to the bedding.

\section{WATERPROOF LAYER}

The addition of a rubber sheet between any mattress and the sheet reduced carbon dioxide build up $(0 \cdot 78-1 \cdot 15 \%$ carbon dioxide). A woollen waterproof layer below the sheet however did allow accumulation on the foam chip mattress $(7.05(0.33) \%)$ and on the foam slab mattress $(4.32(0 \cdot 27) \%)$.

\section{AIRWAY RESISTANCE}

Airway resistance was found to be similar to the reported values for normal infants. ${ }^{13} 14$ The mean resistance when the face was unobstructed was $0.6(0.04) \mathrm{kPa} / \mathrm{l} / \mathrm{sec}$. The greatest resistance was found when the model was face down into the long haired sheepskin (60 $\mathrm{mm}$ fibres). This resistance was 20 $\mathrm{kPa} / \mathrm{/} / \mathrm{sec}$. This represents a pressure swing of about $0.35 \mathrm{kPa}$, which would not be considered enough to disturb or endanger a sleeping infant.

\section{Discussion}

Using a mechanical model of the infant head, we have found that considerable rebreathing occurred when the head was face down into soft under bedding. An infant placed to sleep in the prone position would normally have its head to the side, but this is the only position (unlike supine or lateral) that would allow the face to turn partially or directly into the bedding. Although in our mechanical model, direct face down contact with the surface caused the greatest amount of rebreathing in any of the materials studied, with the head at $45^{\circ}$ to the uncovered long fibre sheepskin, the equilibrium concentration of inspired carbon dioxide (greater than $10 \%$ ) is of concern if it mimics the real life situation. With the head face down the two firmest mattresses (coir fibre and foam slab) gave the best gas dispersal.

Our experiments would indicate that the lethal potential of polystyrene bead filled cushions, reported by Kemp and Thach, ${ }^{11}$ applies to all soft bedding materials. In that study three of the deaths occurred on the first night the baby had slept on the cushion and another 11 of the 19 deaths occurred on the only occasion on which they had been sleeping face down. These events presumably occurred among a considerable population of babies who suffered no ill effects from sleeping on the cushions.

Our results suggest that these deaths may have occurred from a failure of the babies concerned to respond to a high inspired carbon dioxide. Bolton et al have shown that $2 \%$ of an infant population may have inadequate responses to increased inspired carbon dioxide concentrations and paradoxical hypoventilatory response to hypoxia. ${ }^{15}$ If one of these unresponsive babies found itself face down on bedding that did not allow adequate dispersion of expired gases it would not respond and thus it is likely that the first exposure would result in death.

The normal physiological response to rebreathing would be that the hypercapnia and hypoxia would stimulate an increase in ventilation, positional movement, and arousal. McCulloch et al have reported that a near-miss SIDS infant had a significantly higher arousal threshold to alveolar carbon dioxide pressure, $54.9 \mathrm{~mm} \mathrm{Hg}(7.32 \mathrm{kPa})$ compared with 48.4 $(6 \cdot 46)$ for normal infants, ${ }^{16}$ and other authors have identified deficiencies in ventilation and arousal responses in siblings of SIDS victims, infants with a history of apnoea, and others. $^{17-19}$ Neuropathological studies have shown that decreased myelination in motor and arousal areas of the brainstem of SIDS victims suggest that inappropriate arousal responses could have been a factor in the death of these infants. ${ }^{20}$

If the infant arouses, then the next consideration is whether or not the infant could move away from this potentially lethal environment. A conclusion of Kemp and Thach's study of 25 SIDS victims sleeping prone on polystyrene cushions was that movement of the head from side to side to escape the stimuli could exacerbate the situation by causing a deeper pocket to be formed in the cushion for more expired gas trapping. ${ }^{11}$

Controlled lifting of the head in the prone position is not usually accomplished until 3 months of age. ${ }^{21}$ At 3 months of age the infant can maintain the lift with the face at an angle of $45-90^{\circ}$ to the bed. ${ }^{22-24}$ The ability of infants to turn from the prone to the supine position is usually accomplished by 24 weeks. 22232526 This positional change could occur only if the infant is not tightly swaddled. Thus it is possible that a premature or slowly developing infant may not be able to clear its face from the bedding, especially if a depression is formed in the 


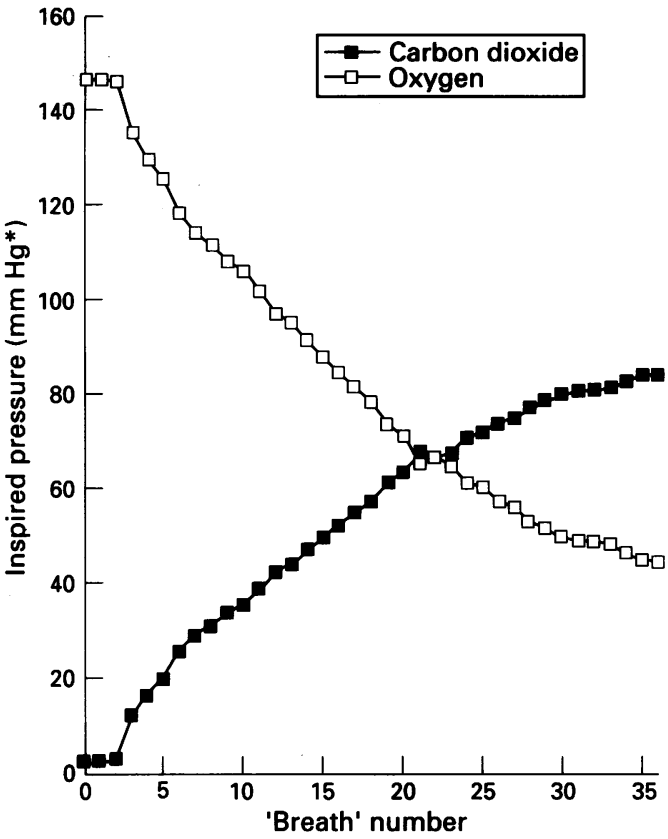

Figure 3 Inspired oxygen and carbon dioxide pressures. The carbon dioxide values are from an actual experimental trace. The oxygen values are computed assuming there is no ventilatory response to the stimulus and that the respiratory quotient stays constant. ${ }^{\star} 1 \mathrm{~mm} \mathrm{Hg}=0.133 \mathrm{kPa}$.

bedding. It also suggests a good reason why there are not so many deaths from SIDS in the first six weeks of life as during this time prone sleeping infants are unlikely to raise their head and place it face down.

If the infant was unable to escape a severely hypercapnic environment, the hypercapnia itself could kill. If inspired air contains $10 \%$ carbon dioxide, this gives an inspired carbon dioxide pressure of $71 \mathrm{~mm} \mathrm{Hg}(9 \cdot 46 \mathrm{kPa})$ with an arterial carbon dioxide pressure being even greater. Carbon dioxide narcosis is associated with arterial carbon dioxide pressure of over 80 $\mathrm{mm} \mathrm{Hg}(10.70 \mathrm{kPa}){ }^{27}$ Figure 3 shows the actual inspired carbon dioxide pressure of the model when face down on soft bedding. Assuming that the carbon dioxide accumulation is the result of reinspiration of all the expired gases, we have calculated the corresponding inspired carbon dioxide pressure assuming a normal respiratory quotient and breathing air. Figure 3 shows that after 30 seconds the inspired carbon dioxide pressure is greater than $50 \mathrm{~mm} \mathrm{Hg}(6.67 \mathrm{kPa})$ and inspired oxygen pressure would be around 65 $\mathrm{mm} \mathrm{Hg}(8.66 \mathrm{kPa})$.

In conclusion, our data imply a dangerous situation for the infant who is put to sleep prone, whose head turns directly into or at $45^{\circ}$ to certain soft bedding materials, and who may be or become unresponsive to the lethal challenge of rebreathing. We believe that all infants should be placed to sleep in the supine position or side with lower shoulder forward unless there is a clear medical reason for sleeping prone (abnormalities of the upper airway or severe gastro-oesophageal reflux). In the recommended sleep positions (back or side) the use of soft bedding would be acceptable, in fact there is evidence to support the use of sheepskins for low birthweight infants, ${ }^{28}$ but if the infant must be placed prone or may possibly turn so that its face is into the soft bedding then a rubber sheet should be placed between mattress and sheet or a firm bedding surface used.

* Since submitting this paper we have tested a mattress featuring holes in the head area and in the carry cot below, which is commonly supplied to British consumers. The mattress behaved exactly like others made from soft materials.

Thanks to G L Bowron Ltd, Alliance Textiles (NZ) Ltd, Windward Skins Ltd, and Burson Nuttal Ltd for supplying bedding materials for investigation and to Sheila Williams for stading materials

AJC's salary was provided by G L Bowron Ltd NZ. CC was supported by a Health Research Council of New Zealand Summer Scholarship.

1 Mitchell EA, Scragg R, Stewart AW, et al. Results from the first year of the New Zealand cot death study. $N Z$ Med $\mathcal{J}$ 1991; 104: 71-6.

2 McGlashan ND. Sudden infant deaths in Tasmania, 1980-1986: a seven year prospective study. Soc Sci Med 1989; 29: 1015-26.

3 Dwyer T, Ponsonby AL, Newman NM, Gibbons LE. Prospective cohort study of prone sleeping position and
sudden infant death syndrome. Lancet $1991 ; 337: 1244-7$.

4 Fleming PJ, Gilbert R, Azaz Y, et al. Interaction between bedding and sleeping position in the sudden infant death syndrome: a population based case-control study. $B M \mathcal{F}$ 1990; 301: 85-9.

5 Senecal J, Roussey M, Defawe G, et al. Procubitus et mort subite inattendue du nourrison. Arch Fr Pediatr 1987; 44: $131-6$

6 de Jonge GA, Engelberts AC, Koomen-Liefting AJ, Kostense PJ. Cot death and the prone sleeping position in the Netherlands. $B M \mathcal{F}$ 1989; 298: 722

7 Engelberts AC, de Jonge GA, Kostense PJ. An analysis of trends in the incidence of sudden infant death in the Netherlands 1969-89. I Paediatr Child Health 1991; 27: 329-33.

8 Taylor BJ. A review of epidemiological studies of sudden infant death in southern New Zealand. $\mathcal{F}$ Paediatr Child Health 1991; 27: 344-8.

9 Stanley FJ, Byard RW. The association between the prone sleeping position and sudden infant death syndrome (SIDS): an editorial overview. $f$ Paediatr Child Health 1991; 27: 325-8.

10 Mitchell EA. Cot death: should the prone sleeping position be discouraged? $\mathcal{P}$ Paediatr Child Health 1991; 27: 319-21.

$11 \mathrm{Kemp}$ JS, Thach BT. Sudden death in infants sleeping on polystyrene-filled cushions. N Engl f Med 1991; 324: 1858-64.

12 Bolton DPG, Cross KW, McKettrick AC. Are babies in carry cots at risk from $\mathrm{CO}_{2}$ accumulation? $B M \mathcal{B} 1972$; iv: $80-1$.

3 Polgar G, Kong GP. The nasal resistance in newborn infants. F Pediatr 1965; 67: 557-67.

14 Schafer AT, Lemke R, Althoff $\mathrm{H}$. Airway resistance of the posterior nasal pathways in sudden infant death. Eur $\mathcal{F}$ Pediatr 1991; 150: 595-8.

15 Bolton DPG. The prevalence of immature respiratory control in a neonatal population. $N Z M e d f \mathscr{f} 1990 ; 103$; 89-92.

16 McCulloch K, Brouillette RT, Guzzetta AJ, Hunt CE. Arousal responses in near-miss sudden infant death syndrome and in normal infants. $\mathcal{F}$ Pediatr 1982; 101: 911-7.

17 Parks YA, Paton JY, Beardsmore CS, et al. Respiratory control in infants at increased risk for sudden death syndrome. Arch Dis Child 1989; 64: 791-7.

18 van der Hal AL, Rodriguez AM, Sargent CW, Platzke ACG, Keens TG. Hypoxic and hypercapneic arousal ACG, Keens TG. Hypoxic and hypercapneic arousal responses and prediction of subsequent
infancy. Pediatrics 1985; 75: 848-54.

19 Shannon DC, Kelly DH, O'Connell K. Abnormal regulation of ventilation in infants at risk for sudden infant death syndrome. N Engl F Med 1977; 297: 747-50.

20 Kinney HC, Brody BA, Finkelstein DM, Vawter GF Mandell F, Gillies FH. Delayed central nervous system myelination in the sudden infant death syndrome. $f$ Neuropathol Exp Neurol 1991; 50: 29-48.

21 Vaughan VC. Developmental pediatrics. In: Behrman RE, Vaughan VC, eds. Nelson textbook of pediatrics. 13th Ed. Philadelphia: WB Saunders 1987: 6-112.

22 Forfar JO, Arneil GC, eds. Textbook of paediatrics. Edinburgh: Churchill Livingstone, 1984

23 Frankenburg WK, Dodds J, Arher P, Shapiro H, Bresnik B Revision of the Denver developmental screening test. Revision of the Denver
Pediatrics 1992; 89: 91-7.

24 Illingworth RS. The development of the infant and young child. Normal and abnormal. Edinburgh: Churchill Livingstone, 1988

25 Beckenridge ME, Vincent EL. Child development: physical and psychologic growth through adolescence. Philadelphia: WB Saunders, 1960

26 Asher C. Postural variations in childhood. London Butterworths, 1975.

27 Wilson JD, Braunwald E, Isselbacher KJ, et al, eds. Harrison principles of internal medicine. 12th Ed. New York McGraw Hill, 1991: 1080

28 Scott S, Cole T, Lucas P, Richards $M$. Weight gain and movement patterns of very low birth weight babies nursed on lambswool. Lancet. 1983; ii: 1014-6. 